\title{
Prevalence of ghostwriting spurs calls for transparency
}

I t's no secret that the names at the top of articles published in medical journals aren't always a good indication of who actually wrote them. What may be surprising to many, though, is just how prevalent ghostwriting appears to have become.

Recently unveiled court documents, for example, show that ghostwriters, paid by the pharmaceutical company Wyeth, produced 26 papers supporting hormone replacement therapy. The documents were obtained by lawyers representing 8400 women who are suing Wyeth for harm they say resulted from the company's hormone drugs.

Listed as sole author on one of the papers was Dr. Barbara Sherwin, a psychology professor at McGill University in Montréal, Quebec. Yet, she actually wrote only portions of the article. The rest was prepared by DesignWrite, a ghostwriting firm hired by Wyeth.

The articles, which appeared in 18 medical journals between 1998 and 2005 , detailed the benefits of the therapy, while minimizing its risks. In 2001, Wyeth's hormone drugs earned sales of nearly US $\$ 2$ billion.

None of that shocked long-time critics of ghostwriting.

"Somewhere between 50\% and $100 \%$ of articles on drugs that appear in journals are ghostwritten," says Dr. David Healy, a psychiatrist at the University of Cardiff in Wales, United Kingdom, and a critic of the drug industry's influence on physicians' drug prescribing habits.

Healy says that ghostwriting "crept up on" the medical profession and became so common by the mid-90s that even senior researchers came to accept it as an ethical practice. Other critics of the practice agree, claiming that many researchers will put their name on a document as primary author even if they just edited it — or only read it and made no changes.

"If you have people like me who say they can't do this, the pharmaceutical

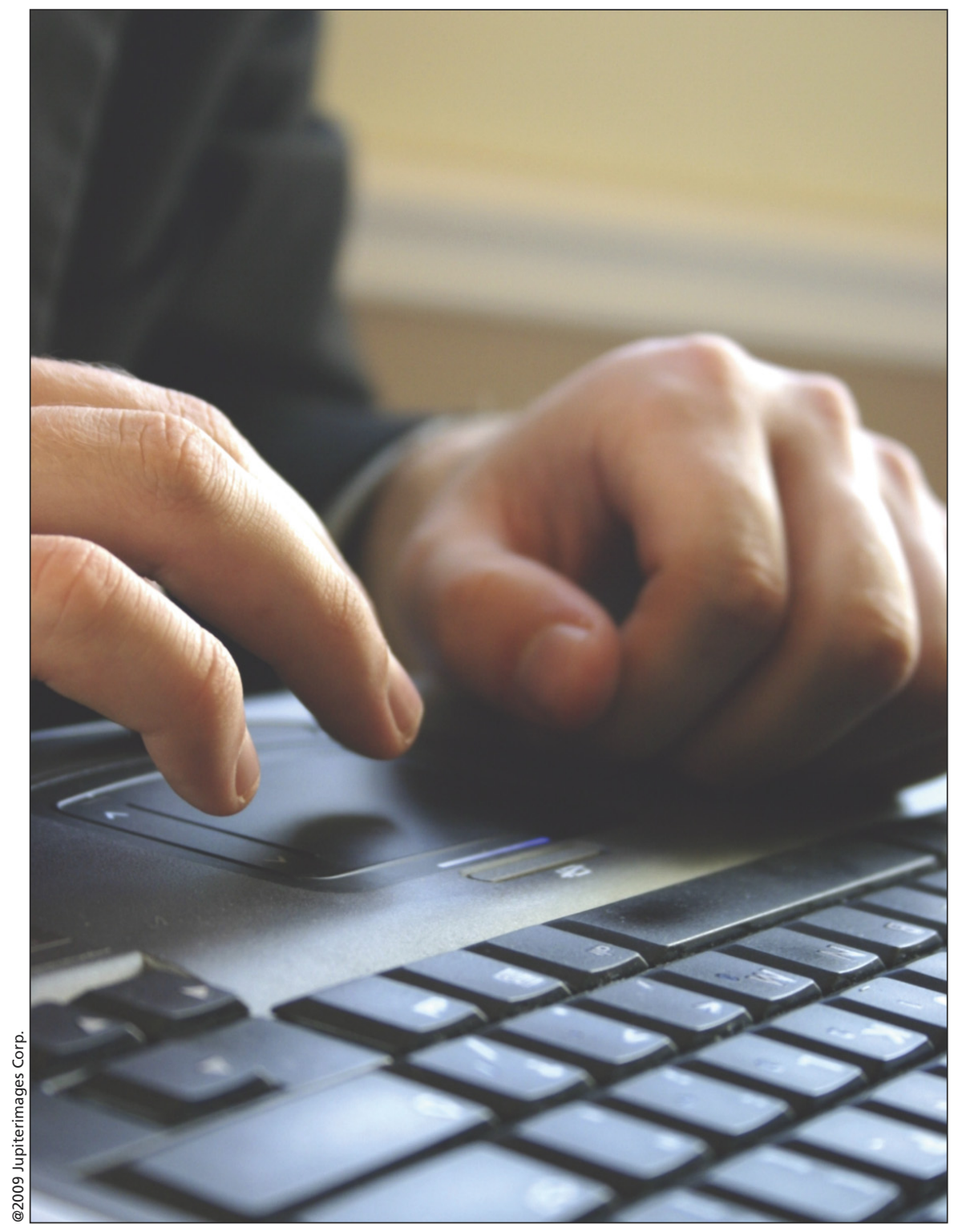

Between $50 \%$ and $100 \%$ of articles on drugs that appear in journals are ghostwritten, says British psychiatrist Dr. David Healy.

industry can easily go elsewhere and find a person who will," says Healy.

Transparency advocates say ghostwriting has become commonplace because it provides substantial benefits to three parties: drug companies, researchers and medical journals. By managing the publication of articles about their products, it is easier for drug companies to spread positive results and bury negative results. This often provides a big boost to drug sales. Having the name of a "key opinion leader" on a study is even better, ghostwriting critics say, because it gives the study an air of independence and respectability.

Many academics show little reluctance in lending their names to articles someone else wrote because it pads 
their resumés, which tends to help them bring in more money on the lecture circuit, says Arthur Schafer, director of the Centre for Professional and Applied Ethics at the University of Manitoba in Winnipeg.

"They sold their credentials for false credit and money," says Schafer.

As for medical journals, they benefit by gaining access to papers on the latest clinical trials for new drug products. Some even accuse medical journals of pandering to the pharmaceutical industry, including turning a blind eye to ghostwriting, so they can publish clinical trial results.

"The articles that the pharmaceutical industry produces are going to include some of the articles on the largest clinical trials that will make the most news," says Sergio Sismondo, a philosophy professor at Queen's University in Kingston, Ontario, who has written extensively on what he calls "ghost management" (PLos Medicine 2007;4:e286).

The effect of ghostwriting on the quality of medical publishing is difficult to assess. First of all, it's hard to prove that an article is ghostwritten unless it turns up during court proceedings, so the extent of the practice can only be estimated. And while some claim ghostwriting is no different than plagiarism, others say it would be acceptable if the process were more transparent.

After all, ghostwriting is common in published literature, from the autobiographies of politicians to the memoirs of celebrities. Of course, in those cases, the name of the ghostwriter typically appears on the cover. Some would like to see that practice adopted by medical publishers.

According to Healy, the best way to increase transparency would be for medical journals to demand that drug companies, if they wish to publish articles they fund, release the data upon which those articles are based. "The biggest problem isn't the ghostwriting, per se, but the lack of access to raw data to check against the conclusions," he says. (For publicly funded research, there is increasing access to the raw data as agencies like the US National Institutes of Health and the Canadian Institutes of Health Research now require that the raw data from publicly funded clinical trials be placed in one of the registries that has met criteria established by the World Health Organization and the International Committee of Medical Journals Editors.)

There have also been some moves in the publishing world to clarify what it means to be an "author" of a study. The International Committee of Medical Journals Editors, for instance, has created guidelines that state that authorship credit should be based on three criteria: substantial contributions to concept, design, acquisition of data or analysis of data; drafting or revising of the article, and final approval of the article.

Ghostwriting was also a subject of discussion at a special session on authorship and contributorship at the Sixth International Congress on Peer
Review and Biomedical Publication in Vancouver, British Columbia, from Sept. 10-12.

"It's valuable to shine a light on what's happening," says Dr. Joseph Ross, an assistant professor with the Mount Sinai School of Medicine in New York City, New York, who has also written about medical ghostwriting (JAMA 2008;299:1800-12). "It makes people somewhat less likely to do it in the future."

Still, some claim, much more can be done to increase transparency in medical publishing, such as: having journals insist that authors describe in detail their contributions to articles; requiring journals to communicate only with authors, not publication planners or medical communication companies; and, most radically, insisting that journals not publish any industry-sponsored research.

Unless something changes, according to Sismondo, there is little incentive for drug companies, researchers or medical journals to do anything about ghostwriting. "For the most part, concern about plagiarism is about fairness, as some people's work is exploited while other people gain unearned credit," Sismondo wrote in an article arguing that medical science is now for sale (Academic Matters, May 2009). "The pharmaceutical industry, always an innovator, has developed a different form of plagiarism, involving only willing participants." - Roger Collier, CMAJ

DOI:10.1503/cmaj.109-3036 